\title{
Reminiscence Cognitive Behavior Therapy for Spiritual Well-Being and Self-Esteem of Cancer Patients
}

\author{
Michiyo Ando*, Tatsuya Morita, Akira Oshima \\ Faculty of Nursing, St. Mary’s College, Kurume city, Fukuoka, Japan. \\ Email: andou@st-mary.ac.jp
}

Received March 31 ${ }^{\text {st }}$ 2011; revised May 10 $0^{\text {th }}, 2011$; accepted May $18^{\text {th }}, 2011$.

\begin{abstract}
The aim of the study was to investigate the potential of Reminiscence Cognitive Behavior Therapy (RCBT) for improvement of spiritual well-being and self-esteem in patients. Five patients received the therapy over three sessions. The patients received RCBT consisting of reminiscence therapy and cognitive behavior therapy. They completed the FACIT-Sp, Rosenberg's Self-Esteem scale, numeric rating scales for Suffering (from 0 to 6 ) and Depression (from 0 to 6). The FACIT-Sp scores increased from $19.2 \pm 4.6$ to $26 \pm 1.6(Z=-1.8, p=0.078, n=5)$, the Self-Esteem scores significantly increased from $40.0 \pm 2.5$ to $45.2 \pm 2.4(Z=-2.0, p=0.042)$, the Suffering scores decreased from $3.6 \pm 2.0$ to $2.0(Z=-1.5, p=0.13)$, and the Depression scores decreased from $2.8 \pm 2.2$ to $1.8 \pm 0.8(Z=-0.9, p=0.357)$. These results suggest that RCBT can improve the spiritual well-being and self-esteem of cancer patients.
\end{abstract}

Keywords: Reminiscence Cognitive Therapy, Cancer Patients, Spiritual Well-Being, Self-Esteem

\section{Introduction}

Many patients experience existential suffering such as a sense of meaningless of life or loss of purpose for living while undergoing anti-cancer treatment. Since spiritual well-being is one of the most important factors in human quality of life, palliation of existential suffering is an important task for medical staff.

Reminiscence therapy is used as a psychological intervention in which patients review stories about their life to address their illness. Reminiscence is defined as memory recall that is usually characterized as simple daydreaming, storytelling, or nostalgia by oneself or with others [1], and reminiscence therapy has an effect on depression and self-esteem for older adults [2]. Life Review is one style of reminiscence therapy, and its efficacy on spiritual well-being of terminally ill cancer patients has been demonstrated [3,4]. However, this efficacy was shown for patients with symptoms and psychological problems or states that are likely to differ from those in patients undergoing treatment who are not terminally ill. Patients under treatment commonly have psychological distress, life anxiety, and depression or uncertainty [5], resulting in low self-esteem.

Cognitive behavior therapy (CBT) is a particularly ef- fective psychotherapy that uses an overall strategy of a blend of verbal procedures and behavioral modification techniques [6]. Previous studies in cancer patients have shown the effects of CBT on anxiety or depression [7], on symptom management in patients with advanced cancer [8], on hot flash [9], and on psychological distress such as anxiety, depression, PTSD symptoms, or coping ability [10-12]. However, there are few interventions for spiritual well-being of cancer patients undergoing treatment such as chemotherapy or radiation therapy $[13,14]$ suggested the utility of CBT integrated with life review for older adults with acute adjustment disorder and somatic symptoms such as sleep and appetite disturbance. This suggests the potential of combining reminiscence therapy with CBT as a psychological intervention.

Here, we propose a new psychological intervention, which we refer to as Reminiscence Cognitive Behavior Therapy (RCBT), for patients undergoing anti-cancer treatment, in which we use both reminiscence therapy and cognitive behavior therapy. CBT may decrease psychological distress or uncertainty, and reminiscence therapy may affect spiritual well-being such as meaning, with a consequent increase in self-esteem. Thus, the present study was performed to investigate the effects of 
RCBT on spiritual well-being, self-esteem and psychological distress such as depression and anxiety.

\section{Methods}

\subsection{Participants}

The participants were cancer patients from a national cancer hospital and a general hospital who met the inclusion criteria of 1) being under anti-cancer treatment; 2) age $\geq 20$ years old; and 3) agreement among primary physicians that the patient would benefit from a psychological intervention. Patients with cognitive impairments or serious mental illness were excluded. Six patients were recruited through primary physicians, but one was unable to complete the study because of a poor physical condition, leaving 5 patients (Table 1) who completed the three sessions.

\subsection{Intervention}

The ethical aspects of the study were approved by the board and ethical committee of St. Mary's College and the National Kyushu Cancer Center. In the first session of RCBT, the patients reviewed the period from diagnosis until the present time and talked about the problems they were currently facing. In a collaborative interview, the therapist and the patient chose suitable CBT techniques. The patients were recommended to practice the techniques at home. In the second session, the patients reviewed the period from their birth to diagnosis and identified strong coping styles in their lives. In the third session, patients talked about their hopes for their future life. In the second and third sessions, the therapist and patients also assessed the RCBT techniques from the previous session.

\subsection{Outcome Measurements}

The Japanese version of the Functional Assessment Chronic Illness Therapy-Spiritual (FACIT-Sp) [15] was used to measure spiritual well-being. Items are scored on 5 -point scales ranging from 4 "strongly agree" to 0 "strongly disagree". The Japanese version of Rosenberg's Self-Esteem Scales [16,17] was used to measure the
Table 1. Backgrounds of patients.

\begin{tabular}{ccccccc}
\hline Patient & Gender & Age & $\begin{array}{c}\text { Primary } \\
\text { cancer }\end{array}$ & $\begin{array}{c}\text { Marital } \\
\text { status }\end{array}$ & Stage ECOG-PS \\
\hline A & Female & 48 & Ovarian & Not married & I & 3 \\
B & Male & 65 & Leukemia & Married & IV & 4 \\
C & Female & 47 & Ovarian & Married & III & 4 \\
D & Female & 55 & Leukemia & Married & III & 4 \\
E & Female & 55 & Breast & Married & III & 3 \\
\hline
\end{tabular}

self-esteem of patients. Ten items are scored on a 5-point scale, ranging from 5 "strongly agree" to 1 "strongly disagree". The validity and reliability of the FACIT-Sp and Self-Esteem Scale are well established. We also used a numeric rating scale for Suffering and Depression (0-6). Statistical comparisons were performed by Wilcoxon sign rank test.

\section{Results}

The results of the questionnaires are shown in Table 2. FACIT-Sp scores increased from $19.2 \pm 4.6$ to $26 \pm 1.6$ $(Z=-1.8, p=0.078, n=5)$, Self-Esteem scores increased from $40.0 \pm 2.5$ to $45.2 \pm 2.4(Z=-2.0, p=0.042)$, Suffering scores decreased from $3.6 \pm 2.0$ to $2.0(Z=-1.5, p$ $=0.131)$ and Depression scores decreased from $2.8 \pm 2.2$ to $1.8 \pm 0.8(Z=-0.9, p=0.357)$. The details for each patient (Table 2) are given in the following paragraphs. Problem, interventions, and effects for each patient are shown in Table 3.

Patient A experienced side effects from chemotherapy and had anxiety about cancer recurrence. She also had interpersonal problems with other patients and concerns about her mother and her work. We used both emotional expression and problem solving to help her to address her interpersonal problems, and psychological education for anxiety about recurrence. Through the reminiscence therapy, she found a purpose for living for her mother and she hoped to return to work. Her Self-Esteem score increased.

Patient B had very advanced leukemia and was isolated in a "clean room". He did not know the truth of his illness and felt uncertainty about his future because the medication had not been effective. He also worried about his family. We used distraction and scheduling of his day

Table 2. Pre- and post-intervention scores on questionnaires.

\begin{tabular}{|c|c|c|c|c|c|c|c|c|}
\hline \multirow[b]{2}{*}{ Patient } & \multicolumn{2}{|c|}{ FACIT-Sp } & \multicolumn{2}{|c|}{ Self-Esteem } & \multicolumn{2}{|c|}{ Suffering } & \multicolumn{2}{|c|}{ Depression } \\
\hline & Pre & Post & Pre & Post & Pre & Post & Pre & Post \\
\hline $\mathrm{A}$ & 23 & 27 & 39 & 42 & 3 & 2 & 2 & 2 \\
\hline B & 17 & 26 & 43 & 48 & 5 & 2 & 5 & 3 \\
\hline $\mathrm{D}$ & 25 & 24 & 39 & 47 & 1 & 2 & 0 & 2 \\
\hline $\mathrm{E}$ & 17 & 28 & 42 & 45 & 3 & 2 & 2 & 1 \\
\hline Mean & $19.2 \pm 4.6$ & $26 \pm 1.6$ & $40 \pm 2.5$ & $45.2 \pm 2.4$ & $3.6 \pm 2.0$ & 2.0 & $2.8 \pm 2.17$ & $1.8 \pm 0.83$ \\
\hline$p$ value & \multicolumn{2}{|c|}{$p=0.08$} & \multicolumn{2}{|c|}{$p=0.04$} & \multicolumn{2}{|c|}{$p=0.13$} & \multicolumn{2}{|c|}{$p=0.36$} \\
\hline
\end{tabular}


Table 3. Main problems, interventions in Reminiscence Cognitive Behavior Therapy, and effects.

\begin{tabular}{|c|c|c|c|}
\hline Patient & Problems & Interventions & Effects \\
\hline A & $\begin{array}{l}\text { - Anxiety about recurrence } \\
\text { - Interpersonal problems } \\
\text { - Loss of meaning to live }\end{array}$ & $\begin{array}{l}\text { - Psychological education } \\
\cdot \text { Emotional expression and assertion } \\
\text { - Review of life }\end{array}$ & $\begin{array}{l}\text { - Decreased anxiety } \\
\text { - Solving interpersonal problems } \\
\text { - Finding a purpose to live }\end{array}$ \\
\hline B & $\begin{array}{l}\text { - Uncertainty about future } \\
\text { - Worry about family } \\
\text { - Bored in the clean room }\end{array}$ & $\begin{array}{l}\text { - Distraction and scheduling } \\
\text { - Support to contact family } \\
\text { - Review of life }\end{array}$ & $\begin{array}{l}\text { - Decreased feeling of uncertainty } \\
\text { - Maintaining contact with family } \\
\text { - Enjoying memories and finding hope }\end{array}$ \\
\hline $\mathrm{C}$ & $\begin{array}{l}\text { - Anxiety about chemotherapy } \\
\text { - Interpersonal problems } \\
\text { - Difficulty of adaptation }\end{array}$ & $\begin{array}{l}\text { - Problem-solving such as gathering information } \\
\cdot \text { Review of life }\end{array}$ & $\begin{array}{l}\text { - Decreased anxiety about chemotherapy } \\
\text { - Found strong coping skills in reflection, benefit of } \\
\text { illness, recognizing important things }\end{array}$ \\
\hline $\mathrm{D}$ & $\begin{array}{l}\text { - Limited life in clean room } \\
\text { - Loss of strength to live }\end{array}$ & $\begin{array}{l}\cdot \text { Distraction and scheduling } \\
\cdot \text { Review of life }\end{array}$ & $\begin{array}{l}\text { - Able to endure therapy through art and due to } \\
\text { decreased boredom - found purpose to live with } \\
\text { benefit finding }\end{array}$ \\
\hline
\end{tabular}

for feelings of uncertainty, and promotion of communication with his family to address his concerns. After the first session, he took a personal computer into his room and enjoyed pleasant memories on the PC. Through the reminiscence therapy, he reviewed his happiest days and found a purpose to live for the future for his family. His FACIT-Sp score increased and his score for Suffering and Depression decreased.

Patient $\mathrm{C}$ was treated before her first chemotherapy session. She had strong anxiety about chemotherapy, strong feelings of loss regarding her body image, interpersonal problems with doctors and other patients, and difficulty in adapting to the hospital environment. We used problem solving to help her to adjust to the hospital environment and to improve her human relationships. After the first session, she collected information about her treatment by herself and was able to manage her anxiety. Through reminiscence, she was able to recall her strong coping styles and talked about the benefits of her illness, including that it gave her time to think about things and that she was now able to recognize the importance of bonds. After intervention, her scores for Depression and Suffering decreased and her FACIT-Sp and Self-Esteem scores increased.

Patient D was interviewed before a transplant due to leukemia. She did not exhibit serious symptoms at the interview, but her daily life was very limited in the clean room. We used distraction and scheduling. She liked art and tried to find enjoyment in daily life. Through reminiscence, she evaluated both the good times and the bad times in her life, and recalled her strong coping ability. She also recognized the tenderness of other people and her score for Self-Esteem increased.

Patient E did not have major symptoms, but she was confused by her lifestyle because she had been working very hard and she felt that this had led to development of her cancer. We used emotional expression in a supportive way. Through reminiscence, she addressed the reasons that she had become ill. She found a way to slow down her busy life and she said that she would live for her family and herself at a slower pace. Her FACIT-Sp score increased.

\section{Discussion}

The increase in FACIT-Sp scores after the intervention suggests that RCBT may be effective for spirituality, although the change in these scores was not statistically significant. For Patients B, C and E, the FACIT-Sp scores increased because they were initially troubled by their lifestyle or purpose to live. Through reminiscence therapy based on trauma theory, they were able to understand their situation and they tried to find meaning in their cancer experiences. Moreover, they became able to evaluate their bad and good experiences with balance. They found positive aspects (benefits) of their illness and a purpose to live, which resulted in peace in mind. According to previous studies $[18,19]$, patients who find benefits in an illness (for example, they became more grateful for each day or more sensitive to their family) are more mentally healthy (QOL) than those who do not. In agreement with these results, finding of benefits may have affected spirituality in the current study. These patients also identified strong coping strategies in their lives through reminiscence and they were able to use this ability to cope with their present problems. On the other hand, CBT affected spirituality and self-esteem through management of psychological distress. Patients B and C had severe psychological distress, including suffering and depression related to anxiety about treatment and uncertainty about the future, and they were able to manage their distress using CBT. 


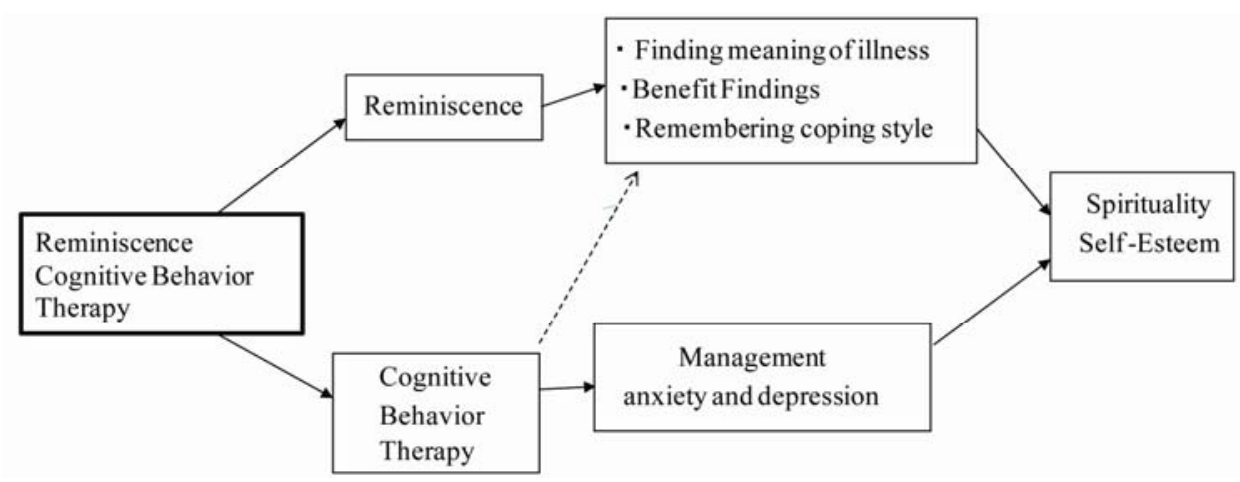

Figure 1. The model of multiplier effects of the Reminiscence Cognitive Behavior Therapy.

Based on our results and previous research showing that CBT may promote finding of benefits and affect QOL [20], we suggest a model (Figure 1) in which reminiscence allows patients to evaluate both the good and bad aspects of their experience and to find meaning in their illness, benefits, and strong coping styles. At the same time, management of psychological distress by CBT contributes to the increase of spiritual well-being and self-esteem. CBT may also affect benefit finding.

The increase in self-esteem that is evident in the study shows the importance of this intervention from the perspective of positive psychology. Research on the positive aspects of cancer is required, since to date most studies have only investigated negative aspects [11]. Most patients under anti-cancer treatment have concerns regarding their social lives, such as body image, economic problems, their job, and their life course. Self-esteem plays an important role in coping with these problems, and self-esteem scores increased in the current study and in an earlier "meaning-making intervention" study [21]. However, our study also showed an effect on spirituality, which was not apparent in Lee et al.

In the current study, Suffering and Depression scores did not decease significantly because Patients A, D and E were not depressed, even though they had anxiety about recurrence and worries about their family. Regarding the CBT techniques, there are many different and useful techniques in CBT. Mishel et al. [5] used cognitive reframing, cancer knowledge, communication and various coping skills, whereas Puentes [14] used correction of distortion of thinking and Penedo et al. [20] used deep-breathing, guided imagery, and progressive muscle relaxation for patients. In the present study, we used emotional expression, problem-solving, distraction, daily scheduling, and psychological education. The choice of different strategies is dependent on the disease stage, period after diagnosis, and progressive side effects, and appropriate techniques should be chosen accordingly. Finally, we note that the number of participants in the current study was small and the disease and stages of the patients were varied. This is a limitation of our findings and larger and more systematic studies are needed to generalize these results.

\section{REFERENCES}

[1] D. Haber, "Life Review: Implementation, Theory, Research, and Therapy," International Journal of Aging and Human Development, Vol. 63, 2006, pp. 153-171. doi:10.2190/DA9G-RHK5-N9JP-T6CC

[2] B. Haight, Y. Michel and S. Hendrix, "The Extended Effects of the Life Review in Nursing Home Residents," International Journal of Aging and Human Development, Vol. 50, No. 2, 2000, pp. 151-168. doi:10.2190/QU66-E8UV-NYMR-Y99E

[3] M. Ando, T. Morita, T. Okamoto and Y. Ninosaka, "One Week STLR Interview Can Improve Spiritual Well-Being of Terminally Ill Cancer Patients," Psycho-Oncology, Vol. 17, 2008, pp. 885-890. doi:10.1002/pon.1299

[4] M. Ando, T. Morita, T. Akechi and T. Okamoto, "Efficacy of Short-Term Life-Review Interviews on the Spiritual Well-Being of Terminally Ill Cancer Patients," Journal of Pain and Symptom Management, Vol. 39, No. 6, 2010, pp. 993-1002. doi:10.1016/i.jpainsymman.2009.11.320

[5] M. H. Mishel, B. B. Germino, K. M. Gil, M. Belyea, I. C. Laney, J. Stewart, L. Porter and M. Clayton, "Benefits from an Uncertainty Management Intervention for African-American and Caucasian Older Long-Term Breast Cancer Survivors," Psycho-Oncology, Vol. 14, No. 11, 2005, pp. 962-978. doi:10.1002/pon.909

[6] A. T. Beck and A. J. Rush, "Cognitive Therapy," In: H. I. Kaplan and B. J. Sadock, Eds., Comprehensive Textbook of Psychiatry/V, 5th Edition, Williams \& Wilkins, Baltimore, 1989, pp. 1541-1550.

[7] S. Greer and S. Moorey, "Adjuvant Psychological Therapy for Cancer Patients," Palliative Medicine, Vol. 11, No. 3, 1997, pp. 240-244. doi:10.1177/026921639701100309

[8] P. Sherwood, B. A. Given, C. W. Given, V. L. Champion, A. Z. Doorenbos, F. Azzouz, S. Kozachik, K. W. Ziner 
and P. O. Monahan, “A Cognitive Behavioral Intervention for Symptom Management in Patients with Advanced Cancer," Oncology Nursing Forum, Vol. 32, 2005, pp. 1190-1198. doi:10.1188/05.ONF.1190-1198

[9] J. S. Carpenter, J. G. Neal, J. Payne, G. Kimmick and A. M. Storniolo, "Cognitive-Behavioral Intervention for Hot Flashes," Oncology Nursing Forum, Vol. 34, No. 1, 2007, pp. 1-8. doi:10.1188/07.ONF.E1-E8

[10] S. Moorey, S. Greer, J. Bliss and M. Law, "A Comparison of Adjuvant Psychological Therapy and Supportive Counseling in Patients with Cancer," Psycho-Oncology, Vol. 7, No. 3, 1998, pp. 218-228. doi:10.1002/(SICI)1099-1611(199805/06)7:3<218::AIDPON308>3.0.CO;2-D

[11] C. M. Bertero, "Affected Self-Respect and Self-Value: The Impact of Breast Cancer Treatment on Self-Esteem and Quality of Life," Psycho-Oncology, Vol. 11, No. 4, 2002, pp. 356-364. doi:10.1002/pon.577

[12] A. McKiernan, S. Steggles, S. Guerin and A. Carr, "A Controlled Trial of Group Cognitive Behavior Therapy for Irish Breast Cancer Patients," Journal of Psychosocial Oncology, Vol. 28, No. 2, 2010, pp. 143-156. doi: $10.1080 / 07347330903570511$

[13] K. Tatrow and G. H. Montgomery, "Cognitive Behavior Therapy Techniques for Distress and Pain in Breast Cancer Patients: A Meta-Analysis," Journal of Behavior Medicine, Vol. 29, No. 1, 2006, pp. 17-27. doi:10.1007/s10865-005-9036-1

[14] W. Puentes, "Cognitive Therapy Integrated with Life Review Techniques: An Eclectic Treatment Approach for Affective Symptoms in Older Adults," Journal of Clinical Nursing, Vol. 13, No. 1, 2003, pp. 84-89. doi:10.1046/j.1365-2702.2003.00828.x

[15] A. H. Peterman, G. Fitchett, M. J. Brady, L. H. Pharm and D. Cella, "Measuring Spiritual Well-Being in People with Cancer: The Functional Assessment of Chronic Illness Therapy-Spiritual Well-Being Scale (FACIT-Sp)," Annual Behavior Medicine, Vol. 24, 2002, 49-58. doi:10.1207/S15324796ABM2401_06

[16] M. Yamamoto, Y. Matusi and Y. Yamashiro, "The Structure of Aspects of Recognized Self," Journal of Japan Education Psychology, Vol. 30, 1982, pp. 64-68.

[17] M. Rosenberg, "Society and the Adolescent Self-Image," Princeton University Press, Princeton, 1965.

[18] P. L. Tomich and V. S. Helgeson, "Is Finding Something Good in the Bad Always Good? Benefit Finding among Women with Breast Cancer," Health Psychology, Vol. 23, No. 1, 2004, pp. 16-23. doi:10.1037/0278-6133.23.1.16

[19] P. L. Tomich and V. S. Helgeson, "Breast Cancer Recurrence and Cognitive Adaptation Theory: Are There Limits?" Journal of Consult Clinical Psychology, Vol. 74, No. 5, 2006, pp. 980-987. doi:10.1037/0022-006X.74.5.980

[20] F. Penedo, I. Molton and J. Dahn, “A Randomized Clinical Trial of Group-Based Cognitive-Behavioral Stress Management in Localized Prostate Cancer: Development of Stress Management Skills Improves Quality of Life and Benefit Findings," Annual Behavior Medicine, Vol. 1, 2006, pp. 261-270. doi:10.1207/s15324796abm3103 8

[21] V. Lee, S. R. Cohe, L. Edgar, et al., "Meaning Making Intervention during Breast or Colorectal Cancer Treatment Improves Self-Esteem, Optimism, and Self-Efficacy," Social Science \& Medicine, Vol. 62, No. 12, 2006, pp. 3133-3145. doi:10.1016/i.socscimed.2005.11.041 